\title{
Have neonatal mortality rates in the state of Qatar become static? A PEARL study analysis
}

\author{
S. Rahman, ${ }^{1,2}$ W. El Ansari, ${ }^{3}$ N. Nimeri, ${ }^{1}$ S. ElTinay, ${ }^{4}$ K. Salameh, ${ }^{1}$ T. Abbas, ${ }^{4}$ M.T. Yousafzai ${ }^{5}$ and A. Bener ${ }^{5}$
}

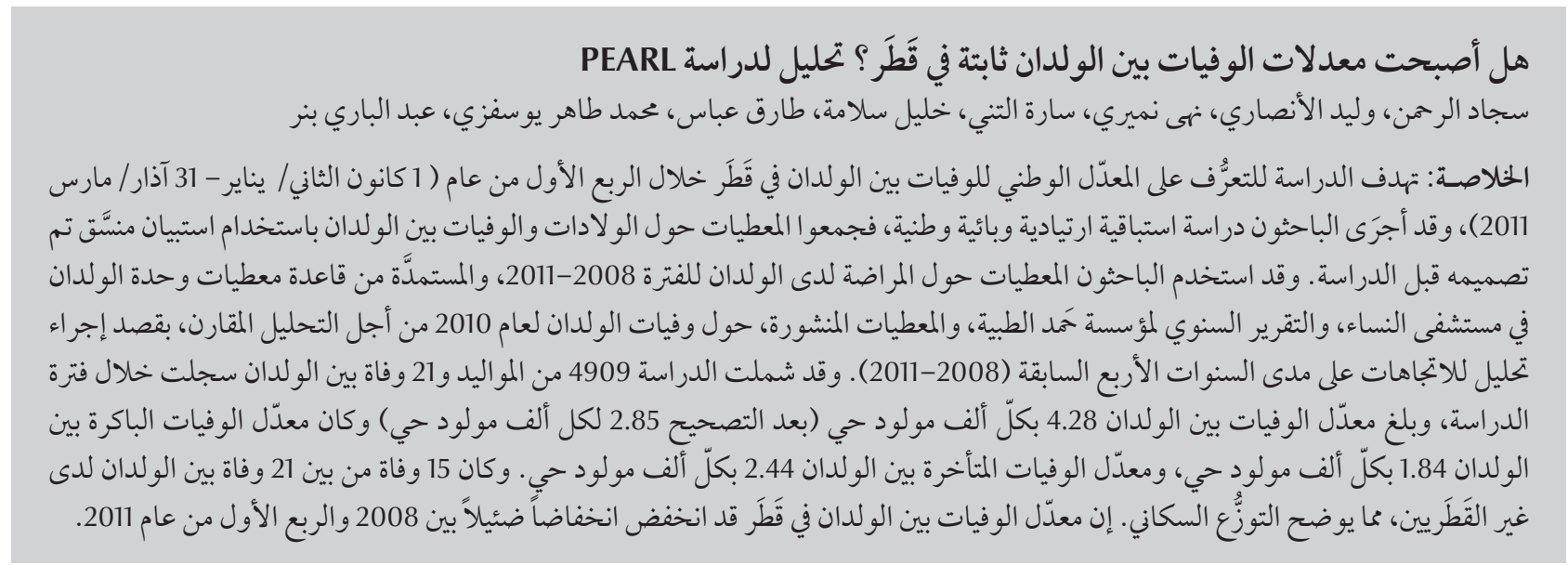

ABSTRACT To ascertain the national neonatal mortality rate in Qatar during the first quarter of 2011 (1 January-31 March), we carried out a prospective pilot national epidemiologic study. Nationwide birth and neonatal mortality data were collected using predesigned, structured questionnaires. To analyse trends over the previous 4 years (2008-2011) we used neonatal mortality data for 2008-2010 from the database of the neonatal unit at the Women's Hospital, annual reports of Hamad Medical Corporation, and published neonatal mortality data for 2010 for comparative analysis. A total of 4909 live births and 21 neonatal deaths were recorded during the study period. The neonatal mortality rate was $4.28 / 1000$ live births (corrected neonatal mortality rate $2.85 / 1000$ ). The early neonatal mortality rate was $1.84 / 1000$ and the late neonatal mortality rate was $2.44 / 1000$ live births. Fifteen of the 21 neonatal deaths were in non-Qatari babies, reflecting the ethnic distribution in the population. Neonatal mortality rates in Qatar declined very little between 2008 and the first quarter of 2011.

\section{Les taux de mortalité néonatale dans l'État du Qatar stagnent-ils ? Analyse de l'étude PEARL}

RÉSUMÉ Pour évaluer le taux de mortalité néonatale national au Qatar pendant le premier trimestre de 2011 (1 ${ }^{\text {er }}$ janvier-31 mars), nous avons mené une étude épidémiologique pilote prospective au niveau national. Les données nationales sur la mortalité à la naissance et la mortalité néonatale ont été recueillies à l'aide de questionnaires préétablis et structurés. Pour étudier les tendances des quatre dernières années (2008-2011), nous avons utilisé les données sur la mortalité néonatale de 2008 à 2010 tirées de la base de données du service des soins néonatals du Women's Hospital (hôpital des femmes), des rapports annuels de la HamadMedical Corporation et les données sur la mortalité publiées pour 2010, à des fins d'analyse comparative. Au total, 4909 naissances vivantes et 21 décès néonatals ont été enregistrés pendant la période de l'étude. Le taux de mortalité néonatale était de 4,28 pour 1000 naissances vivantes (taux de mortalité néonatale corrigé 2,85/1000). Le taux de mortalité néonatale précoce était de 1,84 pour 1000 et le taux de mortalité néonatale tardive était de 2,44 pour 1000 naissances vivantes. Quinze décès néonatals sur vingt-et-un concernaient des enfants qui n'étaient pas Qataris, reflétant la répartition ethnique de la population. Les taux de mortalité néonatale au Qatar ont très peu diminué entre 2008 et le premier trimestre de 2011.

${ }^{7}$ Neonatal Intensive Care Unit, Women's Hospital; ${ }^{5}$ Department of Epidemiology and Medical Statistics; ${ }^{4}$ PEARL Study Research Team, Hamad Medical Corporation, Doha, Qatar.

${ }^{2}$ Department of Paediatrics, Weill Cornell Medical College, Doha, Qatar.

${ }^{3}$ Faculty of Applied Sciences, University of Gloucestershire, Gloucester, United Kingdom (Correspondence to W. El Ansari: walidansari@glos.ac.uk). Received: 09/08/11; accepted: 04/10/11 


\section{Introduction}

Qatar, like other Gulf Cooperation Council countries, has been going through an exponential socioeconomic change over the last 3 decades. The current total population (May 2011) is 1.69 million [1], with approximately $65 \%$ expatriate economic migrants. The vast majority of expatriates are from the Middle East, South and South-East Asia, but almost every country in the world is represented in Qatar's population. Qatar had the highest per capita gross domestic product in the world during 2010 (US\$ 90 149) [2]. The country has a strong political commitment to its development [3]. Reduction in poverty, very high rates of female literacy and investment in maternal and child health care have contributed significantly to the improvement of maternal and neonatal survival [4].

Recent data on the global burden of neonatal deaths suggest that most of the countries constituting the Gulf Cooperation Council, which includes Saudi Arabia, Kuwait, Bahrain, Qatar, the United Arab Emirates and Oman, have done extremely well over the past 4 decades in reducing their neonatal mortality rates $[5,6]$. Among the Gulf Cooperation Council countries, Qatar and the United Arab Emirates have achieved neonatal survival rates which are comparable to those in many developed countries $[4,7,8]$. Qatar is unique in the world since it had achieved most of its Millennium Development Goals by 2007 [9], halfway towards the target year, 2015. This includes Millennium Development Goal 4 (two-thirds reduction in childhood mortality rate). With the rapid expansion in the population and also in health care facilities in Qatar over the last 4 years, the proportion of deliveries in public and private secondary care facilities increased to $17.2 \%$ in 2011 . Therefore there is a need to ascertain the true national neonatal mortality rate and the most recent trends.
The objectives of the current study were to: ascertain the true national neonatal mortality rate in Qatar during the first quarter of 2011; analyse any changes in trends in the neonatal mortality rates between 2008 and 2011; and identify the predominant causes of neonatal mortality.

\section{Methods}

The PEARL Study (Perinatal Neonatal Outcomes Research Study in the Arabian Gulf) is a 3-year prospective, national, perinatal, epidemiologic study. The PEARL Study is a collaborative project between Hamad Medical Corporation, Doha, Qatar and the University of Gloucestershire, Gloucester, United Kingdom. The project aims to build a National Neonatal Perinatal Registry for Qatar called Q-Peri-Reg. The pilot phase of the PEARL Study (1 January-31 March 2011) aimed to: test the data collection tools, methodology and processes; train the research team; develop a tailor-made registry software; and establish a baseline national neonatal, perinatal and maternal mortality and morbidity profile. The current study is a part of this pilot phase. The data were collected prospectively by a full time research team comprising 7 full time physicians: 1 research fellow, 1 research associate and 5 research assistants.

The PEARL study is approved by the Institutional Research Ethics Committee of Hamad Medical Corporation, Qatar (protocol\#9211/09).

\section{PEARL Study definitions}

The limit of viability in Qatar is 24 completed weeks of gestation and/or weight $\geq 500 \mathrm{~g}$ at birth. Since a reliable birth weight is available for all live and stillbirths in Qatar, PEARL Study uses the following WHO definitions, based on ICD-10, to ascertain, analyse and report its neonatal perinatal data [10].

- Live Birth for reporting purposes: The birth of a fetus with a birth weight of $\geq 500 \mathrm{~g}$, or if missing, $\geq 22 \mathrm{com}$ pleted weeks of gestation, or if missing, crown heel length $\geq 25 \mathrm{~cm}$, which after separation from his/her mother, has any signs of life.

- Live Birth for international comparison: The birth of a fetus with a birth weight of $\geq 1000 \mathrm{~g}$, or if missing, $\geq 28$ completed weeks of gestation, or if missing, crown heel length $\geq 35 \mathrm{~cm}$, which after separation from his/her mother, has any signs of life.

The neonatal mortality in babies born at term ( $\geq 37$ weeks gestation) was defined as death between day 0 and day 27 of life. For preterm babies (born at $\leq 36$ weeks gestation), we used adjusted neonatal mortality rates, calculating day 28 of life after first adjusting the gestational age at birth to term (37 weeks). For example, for a baby born at 24 weeks gestation, a death within 118 days of birth ( 90 days to term plus 28 days) was classified as neonatal death. From day 119 onwards, we classified the death as post-neonatal death, even if the baby died in the neonatal intensive care unit.

Neonatal death before day 7 of life (between day 0 and day 6 irrespective of gestation at birth) was defined as early neonatal death, while death between day 7 and 27 (adjusted in preterm babies) was defined as late neonatal death.

The corrected neonatal mortality rate was calculated after excluding babies with lethal congenital anomalies and babies with declared futility before or after birth.

We calculated neonatal mortality rate per 1000 using the number of live births during the study period (1 January-31 March 2011) as the denominator and total neonatal deaths during the study period as numerator. This included babies born before the study period who died during the study period as neonates and excluded babies born during the study period but who died as neonates after the study period. Therefore our neonatal mortality rates represent period 
neonatal mortality and not cohort neonatal mortality.

\section{Data collection}

The birth and neonatal mortality data were collected from the maternity units in Qatar hospitals, including all public and private facilities (3 public and 3 private), from 1 January 2011 until 31 March 2011. The research team collected data on a daily basis, including weekends, on predesigned, structured questionnaires ensuring no new birth or death went unrecorded. Informed consent was obtained from the families on a pre-approved form that was used only for collecting sociodemographic data. Routine medical data were taken from the perinatal registry.

\section{Comparative analysis}

For comparative analysis, data for 2008-2010 were ascertained from the annual reports of the Neonatal Unit at the Women's Hospital and the annual reports of the Department of Medical Statistics and Epidemiology at Hamad Medical Corporation, Qatar, which are published on behalf of the National Health Authority (Department of Health). We compared the neonatal mortality data of the first quarter of 2011 with the yearly data of 2008, 2009 and 2010. We also compared the neonatal mortality data of the first quarter of 2011 with the neonatal mortality data of first quarter of each of 2008, 2009 and 2010. The neonatal mortality data were also stratified and analysed by birth weight and by gestational age. For inter-country comparative analysis of neonatal mortality, we used the World Health Statistics for 2010 [6].

\section{Statistical analysis}

Data were entered into Epi Info, version 3.08, and analysed using SPSS, version 18.09. $P$-value $<0.05$ was considered significant. Mean and standard deviation (SD) were calculated for continuous scale variables, and frequencies with percentage were computed for categorical variables. The continuous variables were compared using student $t$-test. The chi-squared test of significance was used to assess any differences between the categorical variables. The relative risk of mortality was calculated using 2008 data as reference.

\section{Results}

Table 1 shows the national birth and death data during the study period, expressed as live births and total neonatal deaths in each individual obstetric facility. Table 2 depicts the characteristics of each neonatal death which occurred during the study period. The total number of live births during the study period was 4909 (Table 1): of these, $4286(87.3 \%)$ were in the public sector and $623(12.7 \%)$ in the private sector. In terms of hospital, 4063 (82.76\%) births took place in the Women's Hospital, which is the only tertiary care maternity and neonatal centre in Qatar. The remaining 846 (17.24\%) births occurred in secondary care centres. The total number of neonatal deaths was 21, 4 of which were labour room deaths due to futility. Parents of 2 of these futile babies had received antenatal counselling and a joint decision of "Do not resuscitate" (DNR) was reached before birth while the 2 remaining babies were declared DNR by the attending physician following clinical assessment after birth (Table 2). Three more babies who died in the neonatal intensive care unit were also declared futile and declared DNR following parental consent: the first had anencephaly (died on day 2 of life in low dependency unit); the second was born extremely premature at 23 weeks (died on day 1 in low dependency unit); and the third had Potter Syndrome (died on day 1 of life in the neonatal intensive care unit).

\begin{tabular}{|c|c|c|c|c|}
\hline \multirow[t]{2}{*}{ Facility } & \multirow[t]{2}{*}{ Live births $^{\mathrm{a}}$} & \multicolumn{3}{|c|}{ Neonatal deaths } \\
\hline & & Total & Early & Late \\
\hline Women's Hospital ${ }^{\mathrm{b}}$ & 4063 & 19 & 9 & 10 \\
\hline Hamad General Hospital ${ }^{b, c}$ & 0 & $2^{\mathrm{d}}$ & 0 & 2 \\
\hline Al Khor Hospital ${ }^{b}$ & 223 & 0 & 0 & 0 \\
\hline Al Ahli Hospitald & 435 & 0 & 0 & 0 \\
\hline Doha Clinic Hospital ${ }^{d}$ & 94 & 0 & 0 & 0 \\
\hline Al Emadi Hospital ${ }^{\mathrm{d}}$ & 94 & 0 & 0 & 0 \\
\hline Total & 4909 & 21 & 9 & 12 \\
\hline Neonatal mortality rate (per & & 4.28 & 1.84 & 2.44 \\
\hline
\end{tabular}

${ }^{a}$ Home births constitute only $0.5 \%$ of total births; they are included in the Women's Hospital data where they have to be reported for mandatory birth registration and hence are also included in the total.

${ }^{b}$ Public hospitals.

'There is no maternity ward in Hamad General Hospital, hence no births were recorded here but it has Qatar's only paediatric intensive care unit, where 2 neonatal deaths were recorded.

dPrivate hospitals. 


\begin{tabular}{|c|c|c|c|c|c|c|}
\hline Sex & Nationality & $\begin{array}{l}\text { Gestation } \\
\text { (weeks) }\end{array}$ & $\begin{array}{l}\text { Birth weight } \\
(\mathrm{g})\end{array}$ & $\begin{array}{l}\text { Alive } \\
\left.(\text { days })^{\mathrm{a}}\right)\end{array}$ & $\begin{array}{l}\text { Place of } \\
\text { death }\end{array}$ & Cause of death/comments \\
\hline \multicolumn{7}{|c|}{ Early neonatal death } \\
\hline M & Jordanian & 23 & 570 & $11 \mathrm{~h}$ & $\mathrm{NICU}$ & Extreme prematurity, postnatal DNR \\
\hline M & Palestinian & 39 & 790 & 2 & $\mathrm{NICU}$ & $\begin{array}{l}\text { Severe IUGR, severe renal and pulmonary } \\
\text { hypoplasia, }\end{array}$ \\
\hline $\mathrm{F}$ & Indian & 29 & 1250 & $45 \mathrm{~min}$ & LR & Potter syndrome, pulmonary hypoplasia \\
\hline $\mathrm{F}$ & Jordanian & 30 & 1730 & $30 \mathrm{~min}$ & LR & $\begin{array}{l}\text { Holoprocencephaly; multiple congenital } \\
\text { anomalies }\end{array}$ \\
\hline M & Palestinian & 32 & 1830 & 1 & $\mathrm{NICU}$ & $\begin{array}{l}\text { Potter syndrome, bilateral multicystic } \\
\text { kidneys, pulmonary hypoplasia }\end{array}$ \\
\hline M & Saudi Arabian & 38 & 2160 & 2 & $\mathrm{NICU}$ & Anencephaly \\
\hline $\mathrm{F}$ & Syrian & 38 & 2190 & $35 \mathrm{~min}$ & LR & Meckle-Gruber syndrome, antenatal DNR \\
\hline $\mathrm{F}$ & Pakistani & 40 & 2950 & 2 & $\mathrm{NICU}$ & Diaphragmatic hernia, lung hypoplasia, PPHN \\
\hline $\mathrm{F}$ & Pakistani & 23 & 545 & $4 \mathrm{~min}$ & LR & Extreme prematurity \\
\hline \multicolumn{7}{|c|}{ Late neonatal death } \\
\hline M & Syrian & 23 & 610 & 45 & $\mathrm{NICU}$ & $\begin{array}{l}\text { Extreme prematurity, CLD, bacterial \& fungal } \\
\text { sepsis, endocarditis }\end{array}$ \\
\hline $\mathrm{F}$ & Qatari & 24 & 640 & 89 & $\mathrm{NICU}$ & Extreme prematurity, severe sepsis \\
\hline M & Yemeni & 24 & 780 & 40 & $\mathrm{NICU}$ & Extreme prematurity, NEC, sepsis \\
\hline $\mathrm{F}$ & Filipino & 24 & 810 & 16 & $\mathrm{NICU}$ & Extreme prematurity, septic shock \\
\hline $\mathrm{F}$ & Ghanaian & 26 & 840 & 16 & $\mathrm{NICU}$ & Extreme prematurity \\
\hline M & Jordanian & 29 & 1210 & 35 & $\mathrm{NICU}$ & $\begin{array}{l}\text { Prematurity, pulmonary interstitial } \\
\text { emphysema, fulminant sepsis }\end{array}$ \\
\hline $\mathrm{F}$ & Saud Arabian & 39 & 1545 & 8 & $\mathrm{NICU}$ & IUGR, PPHN, sepsis \\
\hline M & Philippino & 36 & 1895 & 8 & $\begin{array}{l}\text { Surgical } \\
\text { theatre }\end{array}$ & $\begin{array}{l}\text { Congenital anomalies, CHD, TEF, dysplastic } \\
\text { left kidney }\end{array}$ \\
\hline $\mathrm{F}$ & Qatari & 37 & 1950 & 10 & $\mathrm{NICU}$ & $\begin{array}{l}\text { Congenital diaphragmatic hernia, } \\
\text { hypoplastic lungs, severe PPHN }\end{array}$ \\
\hline $\mathrm{F}$ & Qatari & 40 & 2370 & 19 & $\mathrm{NICU}$ & Hypoplastic left heart syndrome \\
\hline M & Qatari & 37 & 2570 & 8 & PICU & Fulminant sepsis, DIC \\
\hline $\mathrm{F}$ & Qatari & 38 & 3300 & 9 & $\mathrm{NICU}$ & Meconium aspiration syndrome, severe PPHN \\
\hline
\end{tabular}

anless otherwise indicated.

$M=$ male $; F=$ female $; N I C U=$ neonatal intensive care unit $D N R=$ do not resuscitate $; I U G R=$ intrauterine growth restriction; $L R=l a b o u r$ room; $P P H N=$ persistent pulmonary hypertension of the newborn; $C L D=$ chronic lung disease; $N E C=$ necrotizing entercolitis; $C H D=$ congenital heart disease; $T E F=$ tracheo-oesophageal fistula; $P I C U=$ paediatric intensive care $u n i t ; D I C=$ disseminated intravascular coagulopathy.

Low birth weight $(\leq 2500 \mathrm{~g})$ was noted in 17 of the babies who died; 6 of these were term babies with intrauterine growth restriction. The mean birth weight of the babies who died was 1599.5 g (range 570-3300 g; SD 843.17) (Figure 1A). Prematurity accounted for 11 of the 21 neonatal deaths, including 6 with extreme prematurity $(\leq 28$ weeks gestation). The mean gestational age of the babies who died was 32 (range 23-40, SD 6.53) weeks (Figure 1B).

Congenital anomalies were found in 10 babies; these included 7 with declared futility on antenatal ultrasound scan. Among the dead babies, 15 were non-Qatari and 9 were males (Table 2). All neonatal deaths occurred in tertiary care neonatal and paediatric intensive care units of Hamad Medical Corporation. There were no neonatal deaths in the private facilities nor in any secondary care unit.

The neonatal mortality rate was 4.28/1000 live births during the study period and the corrected neonatal mortality rate (calculated after excluding lethal congenital anomalies and futility) was $2.85 / 1000$ live births. The early neonatal mortality rate was $1.84 / 1000$ live births and late neonatal mortality rate 2.44/1000 live births (Tables 1 and 3). The neonatal mortality rate declined steadily (Figure 2) from 2008 till the first quarter of 2011 (relative risk 0.94; 95\% confidence interval 0.85-1.04). However, the decline was not statistically significant $(P<0.05)$. The early neonatal mortality rate also showed a non-significant decline $(P<0.05)$. The late neonatal mortality rate, however, remained static. 
A
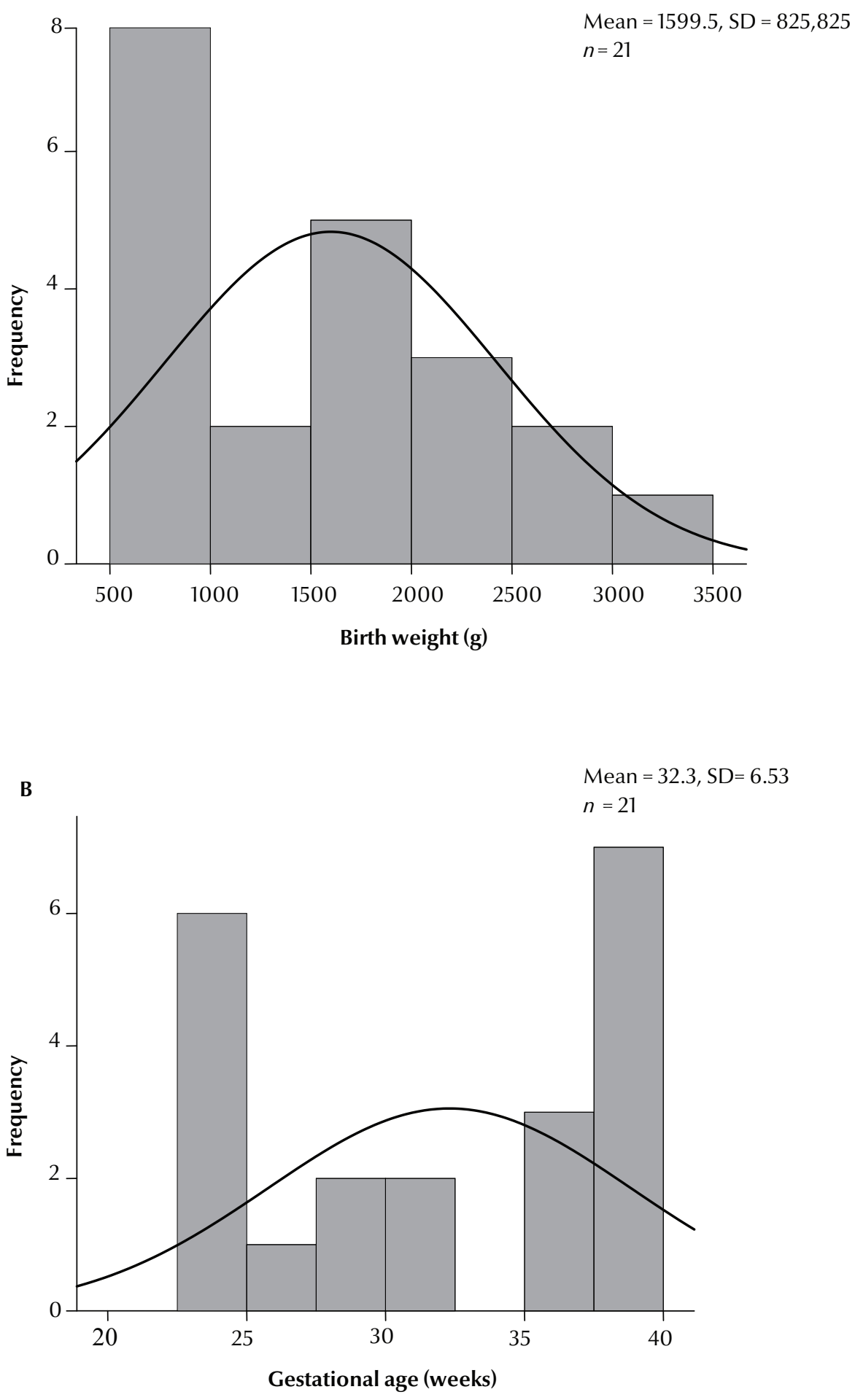

Figure 1 Birth weight (A) and gestational age (B) curves among neonatal deaths, Doha, 2011

\section{Discussion}

Qatar's sociodemographic and health services profile is changing very fast due to the recent economic boom. Over the past 4 years, with increasing population and expanding health care services, many secondary care maternity and neonatal units have been established across the country. Women Hospital's share of national births has now dropped from $98.0 \%$ during
1977-2007 to $82.76 \%$ owing to the shift of low risk deliveries to secondary care facilities; consequently, the number of deliveries in public and private secondary care hospitals increased, from $\leq 1.0 \%$ to $17.24 \%$. 


\begin{tabular}{|c|c|c|c|c|c|c|}
\hline \multirow[t]{2}{*}{ Variable } & \multicolumn{4}{|c|}{ Year } & \multirow[t]{2}{*}{$P$-value } & \multirow[t]{2}{*}{$\mathbf{R R}(95 \% \mathrm{Cl})$} \\
\hline & 2008 & 2009 & 2010 & 2011 & & \\
\hline \multicolumn{7}{|c|}{ Comparison of annual neonatal mortality rate (2008-2010) with first quarter neonatal mortality rate (2011) } \\
\hline Live births & 14899 & 15531 & 16416 & 4909 & & \\
\hline Neonatal deaths & 80 & 65 & 79 & 21 & & \\
\hline Neonatal mortality rate ${ }^{\mathrm{a}}$ & 5.4 & 4.3 & 4.11 & 4.28 & 0.269 & $0.94(0.85-1.04)$ \\
\hline Early neonatal deaths & 31 & 34 & 38 & 9 & & \\
\hline Early neonatal mortality rate & 2.5 & 2.2 & 1.94 & 1.84 & 0.537 & $0.95(0.81-1.11)$ \\
\hline Late neonatal deaths & 49 & 31 & 42 & 12 & & \\
\hline Late neonatal mortality rate $\mathrm{a}^{\mathrm{a}}$ & 2.9 & 2.1 & 2.17 & 2.44 & 0.356 & $0.94(0.83-1.06)$ \\
\hline \multicolumn{7}{|c|}{ Comparison of first quarter neonatal mortality rate $(2008-2010)$ with first quarter neonatal mortality rate (2011) } \\
\hline Live births & 3498 & 3660 & 3777 & 4909 & & \\
\hline Neonatal deaths & 19 & 21 & 19 & 21 & & \\
\hline Neonatal mortality rate ${ }^{\mathrm{a}}$ & 5.4 & 5.7 & 5.0 & 4.28 & 0.36 & $0.8(0.4-1.4)$ \\
\hline Early neonatal deaths & 11 & 12 & 11 & 9 & & \\
\hline Early neonatal mortality rate & 3.1 & 3.3 & 2.9 & 1.84 & 0.15 & $0.5(0.2-1.3)$ \\
\hline Late neonatal deaths & 8 & 9 & 8 & 12 & & \\
\hline Late neonatal mortality rate ${ }^{\mathrm{a}}$ & 2.3 & 2.5 & 2.1 & 2.44 & 0.88 & $1.1(0.4-2.6)$ \\
\hline
\end{tabular}

aPer 1000 live births.

$R R=$ relative risk of mortality between 2008 (reference) and 2011.

$\mathrm{Cl}=$ confidence interval.

Our study shows that Qatar's neonatal mortality rate had a persistent but very slow downward trend between 2008 and 2011. The same trend was experienced in many developed countries during the 1990s $[11,12]$. This suggests that neonatal mortality rates have a limit to improvement, after which they become static. This is probably due to the fact that the unexpected birth of babies with lethal congenital anomalies or acquired problems like fulminant sepsis and severe perinatal asphyxia will never become zero. Qatar's 2011 neonatal mortality rate $(4.28 / 1000)$ is the best among the GulfCooperation Council countries, and is similar to the 2010 neonatal mortality rate in the United States of America, Canada and New Zealand [6]. Although some countries, e.g. Sweden, Japan and Singapore, have much better neonatal mortality rates [6], in-depth analysis of causes of neonatal deaths, difference in social and cultural values directing obstetric practices, and the method of reporting of deaths reduces this gap considerably.

The ethnic distribution of neonatal mortality between Qatari and
non-Qatari babies in our study reflects the general ethnic distribution in the population. Hence, the neonatal mortality rate appears to be independent of ethnicity.

Low birth weight $(\leq 2500 \mathrm{~g})$ is the major cause of neonatal deaths in Qatar. In our study $81 \%$ of neonatal deaths were among low birth-weight babies. This included preterm babies who were otherwise appropriate for gestational age, as well as term and preterm babies who had intra uterine growth restriction. Term intrauterine growth restriction constituted $35 \%$ of total low birth weight babies. The birth weight distribution curve for our dead babies is markedly skewed to the left compared with the gestational age distribution curve for the same babies. This pattern is in marked contrast to the developed world countries in which prematurity with birth weight appropriate for gestational age constitutes the major cause of neonatal deaths [6].

Prematurity was the second biggest cause of neonatal deaths in our study. Since the mid-1990s, Qatar has had a very busy and active assisted reproductive unit. Hence, similar to the pattern in developed world countries, assisted reproduction has resulted in increased numbers of preterm and multiple births over the last 2 decades [7]. Therefore the trend of increasing numbers of preterm births accompanied by a parallel increase in preterm mortality at the limits of viability and an attending increase in morbidity will continue despite rapidly advancing neonatal intensive care technology. This is the profile of neonatal survival shared by all developed and rapidly developing countries.

Lethal congenital anomalies were the third leading cause of neonatal mortality in our study. According to the most recent global report, the Arab countries have the highest incidence of birth defects in the world [13]; the reported incidence in Qatar is 74 per 1000 births. Consanguinity may be an underlying reason of high incidence of birth defects. The overall incidence of consanguinity is $40 \%-70 \%$ among Gulf Cooperation Council countries [14], and the incidence can be very high in 


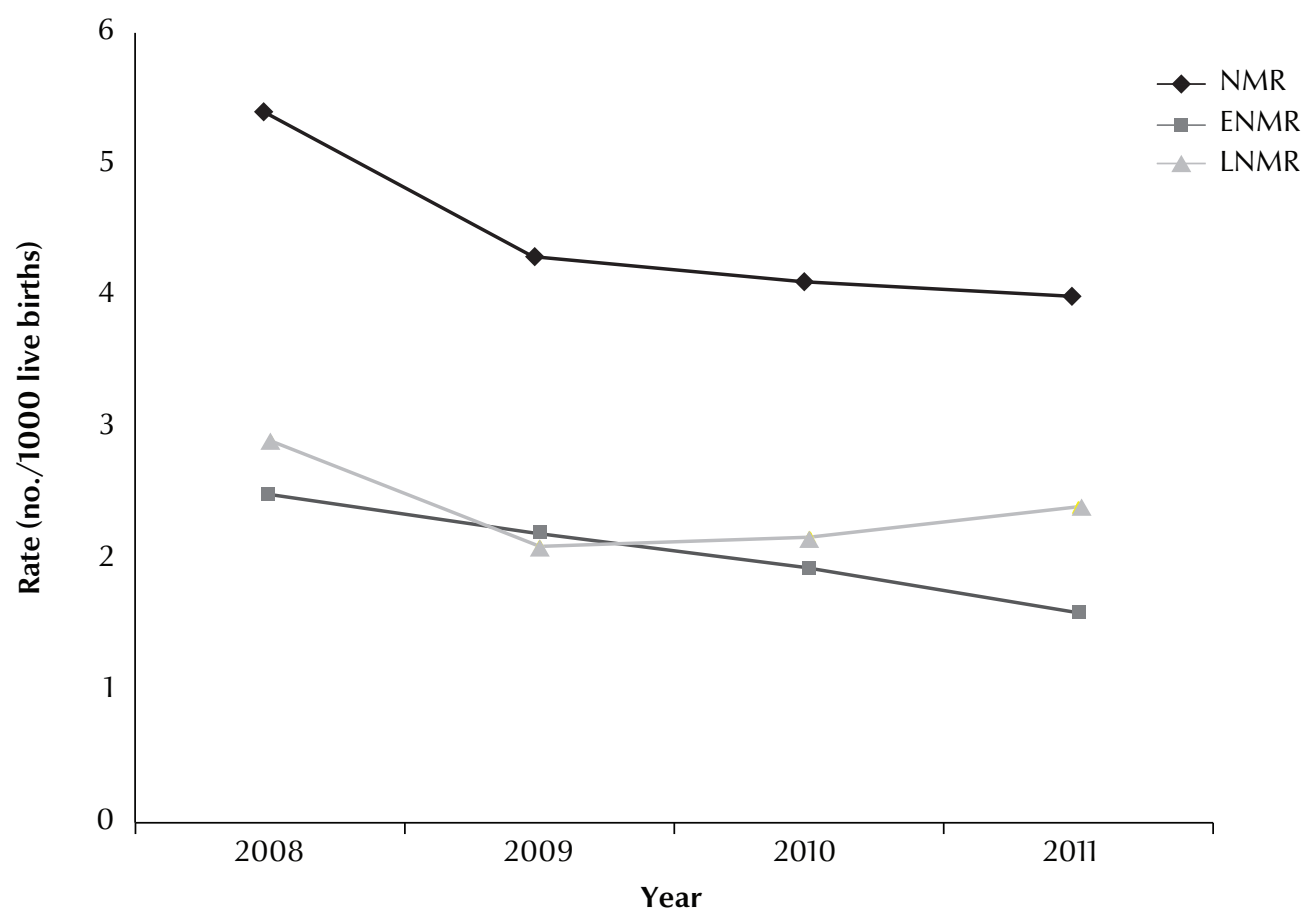

Figure 2 Trends in neonatal mortality rate (NMR), early neonatal mortality rate (ENMR) and late neonatal mortality rate (LNMR) in Qatar 2008-2011

some individual tribes. The incidence of consanguinity in Qatar is 54\% [14]. Consanguinity has a known association with preterm births [15], as well as with perinatal wastage [16]. In our study, $35 \%$ of babies with congenital anomalies had declared futility on antenatal ultrasound scan.

The parents of 5 of the babies who died in our study had consented to a "do not resuscitate" policy during antenatal counselling. Because of local sociocultural conventions and religious beliefs, the parents preferred this approach rather than termination of pregnancy. With the same antenatal scenario in the more developed countries, these pregnancies would have been terminated and would never have been counted or included in the neonatal mortality rates. This point was highlighted pertinently in a recent report on the impact of varying practices of termination of very preterm pregnancies among European countries on neonatal mortality rates [17]. According to this report, most terminations were due to congenital anomalies and contributed substantially to overall fetal mortality rates during the second trimester [17]. If Qatar had a similar rate of antenatal terminations of congenital anomalies during the second trimester, the neonatal mortality rate would have been $1-2 / 1000$, similar to that of Japan and Singapore, which have the best numerical neonatal survival outcomes [6]. Therefore it is extremely important to document the background, sociocultural situation and religious beliefs which drive obstetric practice in each society before comparing numerical achievements of health indicators. The same points were highlighted in a 2003 study reviewing the heterogeneous composition, practices and reporting systems across Europe [18].

Sepsis was associated with $35 \%$ of deaths in our study and was the fourth most common cause of neonatal mortality; about three-quarters of the cases of sepsis were associated with prematurity. Two babies delivered at term had very severe early-onset sepsis of perinatal origin. Both died on day 8 of life despite full intensive care support. In most developed countries, prematurity is the first and sepsis the second most common cause of neonatal death [7].

The health care arena in Qatar is changing swiftly. Qatar provides universal health cover for all its citizens, irrespective of ethnicity. Maternal and neonatal health care in Qatar is not only expanding horizontally; it is also developing vertically. Our study has shown that all neonatal deaths took place in neonatal and paediatric intensive care units of the only tertiary care facility in the country. This is because all mothers with high-risk pregnancies are usually transferred before delivery to tertiary care hospitals. Any high risk babies delivered in secondary care hospitals are transferred to tertiary care hospital. Our findings have also shown that the contribution of private hospitals and public sector secondary care units has now increased to $17.24 \%$ of total deliveries. This trend is likely to increase further in near future. Neonatal mortality among high risk babies is known to be lower 
when they are born in hospitals with tertiary care obstetric and neonatal intensive care facilities [19]. As with other successful regionalized perinatal systems, e.g. in British Colombia, Canada [20], an authentic reporting of maternal, perinatal and neonatal outcome indicators in Qatar will be markedly facilitated by the development of a prospective national electronic perinatal registry.

\section{Conclusion}

The State of Qatar has achieved neonatal mortality rates comparable to the rates in most developed countries of the world; both in the west and east. Qatar's neonatal mortality rates seem to have reached a plateau. Any further improvement in neonatal survival will require reduction in the number of lethal congenital anomalies and improved care of preterm and low birth weight babies.

\section{Funding}

The Perinatal Neonatal Outcomes Research Study in the Arabian Gulf (PEARL Study) has been exclusively funded by Qatar National Research Fund (www.qnrf.org) [the research funding body of Qatar Foundation (www.qf.org.qa)] through the third cycle of its National Priorities Research Programme; grant number QNRFNPRP-09-390-3-097.

\section{Acknowledgements}

We thank Dr Emirah A. Latiph-Tamano, Dr Faiza Rani, Ms Rabia Aman (PEARL Study research assistants), Mariam Abdel Hafez (PEARL Study secretary) and the management of all public and private maternity hospitals in Qatar for their support in assembling the national births and neonatal deaths data for Qatar's Perinatal Registry (QPeri Reg).

\section{References}

1. Qatar Population. Qatar Statistics Authority, 2010 (http:// www.qsa.gov.qa/)

2. Country economic reports and GDP data: Qatar. New York, Global Finance, 2011 (http://www.gfmag.com/ gdp-data-country-reports/195-qatar-gdp-country-report. html\#axzz28MAE5KHY, accessed 6 October 2011).

3. Qatar National Vision 2030. Doha, General Secretariat for Development Planning (http://www.gsdp.gov.qa/portal/page/ portal/gsdp_en/qatar_national_vision/qnv_2030_document. accessed 6 October 2011).

4. Rahman $\mathrm{S}$ et al. Socioeconomic associations of improved maternal, neonatal, and perinatal survival in Qatar. International Journal of Women's Health, 2010, 2:311-318.

5. Rajaratnam JK, Marcus JR, Flaxman AD. Neonatal, post neonatal, childhood, and under-5 mortality for 187 countries, 1970-2010: a systematic analysis of progress towards Millennium Development Goal 4. Lancet, 2010; 375:1988-2008.

6. World Health Statistics 2010. Geneva, World Health Organization, 2011 (www.who.int/whosis/whostat/2010/en/index. html, accessed 6 October 2012).

7. Salameh $\mathrm{K}$ et al. An analytic study of trends in perinatal and neonatal mortality rates in the State of Qatar over a 30 years period (1977-2007): a comparative study with regional and developed countries. Journal of Perinatology, 2009, 29:765-770.

8. Parappil $\mathrm{H}$ et al. Outcomes of $28+1$ to $32+0$ Weeks Gestation Babies in the State of Qatar: finding facility-based cost effective options for improving the survival of preterm neonates in low income countries. International Journal of Environmental Research and Public Health, 2010, 7:2526-2542.

9. The Millennium Development Goals in the State of Qatar. Doha, Qatar Statistics Authority, 2008 (http://www.qsa.gov.qa/eng/ pdf/Millinum_development_goals/MDG_2REPORT_EN.pdf, accessed 6 October 2011).

10. WHO. ICD-10: International statistical classification of diseases and related health problems; instruction manual. Geneva: World Health Organisation, 2004:2.
11. Horbar JD et al. Trends in mortality and morbidity for very low birth weight infants, 1991-1999. Pediatrics, 2002, 110:143-151.

12. Tommiska $\vee$ et al. No improvement in outcome of nationwide extremely low birth weight infant population between 19961997 and 1999-2000. Pediatrics, 2007, 119:29-36.

13. March of Dimes. The global and regional toll of preterm birth (White Paper). 2009:1-20 (http://www.efcni.org/ fileadmin/Daten/Web/Brochures_Reports_Factsheets_ Position_Papers/White_Paper_March_of_Dimes/100511_ MOD002-WhitePaper_save.pdf, accessed 19 September 2012).

14. Bener AB, Hussain R. Consanguineous unions and child health in the State of Qatar. Paediatric \& Perinatal Epidemiology, 2006, 20:372-378.

15. Mumtaz $\mathrm{G}$ et al. Consanguinity: a risk factor for preterm births at less than 33 weeks gestation. American Journal of Epidemiology, 2010, 172:1424-1430.

16. Assaf $\mathrm{S}$ et al. Consanguinity and reproductive wastage in the Palestinian territories. Paediatric \& Perinatal Epidemiology, 2009, 23:107-115.

17. Papiernik E et al. Termination of pregnancy among very preterm births and its impact on very preterm mortality: results from ten European population based cohorts in the $\mathrm{MO}$ SAIC study. British Journal of Obstetrics and Gynaecology, 2008, 115:361-368.

18. Lack $\mathrm{N}$ et al. Methodological difficulties in the comparison of indicators of perinatal health across Europe. European Journal of Obstetrics, Gynaecology \& Reproductive Biology, 2003, 111:s33-s44.

19. Cifuentes $\mathrm{J}$ et al. Mortality in low birth weight infants according to level of neonatal care at hospital of birth. Pediatrics, 2002, 109:745-751

20. Perinatal Database Registry. British Colombia, Provincial Health Services Authority, 2010 (http://bcrcp.xplorex.com/ Perinatal\%20Database\%20Registry.htm, accessed 6 October 2012). 